\title{
On the Processing of Decimated Signals
}

\author{
Rimantas PUPEIKIS \\ Institute of Mathematics and Informatics \\ Akademijos 4, LT-08663 Vilnius, Lithuania \\ e-mail: pupeikis@ktl.mii.lt
}

Received: February 1 2008; accepted: September 42008

\begin{abstract}
The aim of the given paper is development of a recursive approach for calculating the statistics of decimated realizations of a basic discrete-time signal, obtained by sampling a continuous-time one. The statistics values are calculated without storing decimated realizations in the memory of a computer. In such a case, only all samples of the basic discrete-time signal are required. The summing calculation amount has been significantly reduced here by applying recursive expressions that use, in the current operation, the respective statistic obtained by processing the samples of a previous decimated realization. We prove the corollaries referring to recursive statistics calculation and present here an example. The results of calculation of the total quantity of computer operations for a different amount of decimated signals are also given and compared to that, determined by using the ordinary formulas.
\end{abstract}

Keywords: signals, processing, decimation, Nyquist frequency, realization, statistics, computer operations.

\section{Introduction}

While processing discrete-time signals, there arises a problem to retrieve maximal information as well as to reduce the amount of calculations on samples. In such a case, the data decimation by means of a downsampling operation is used (Proakis and Manolakis, 1996). This is a time-scaling operation that is equivalent to changing the sampling rate $F_{s}$ of an analogous signal from $1 / T_{s}$ to $1 / 2 T_{s}$, where $T_{s}$ is a sampling period and its reciprocal $1 / T_{s}=F_{s}$, i.e., decreasing the sampling rate twice. In such a case, the number of samples to be processed decreases twice, as well. In general, the basic sampling frequency $F_{s}$ could be decreased by a fixed integer number of times. It is known that the decimation process ought to be stopped before the frequency content of the signal is above the new Nyquist frequency $F_{N}=F_{s} / 2$. The sampling rate determination techniques are proposed for discrete process control and identification of dynamic systems (Ȧström, 1969; MacGregor, 1976; Payne et al., 1975; Ljung, 1999; Xin et al., 1995), as well as for improving spectral resolution while solving a spectral estimation problem (Liu and Mintzer, 1978; Quirk and Liu, 1983; Villalba and Walker, 1989; Wang et al., 2007). On the other hand, frequently it is important, first of all, to calculate simple statistical characteristics of decimated realizations without storing them in the memory of a computer, e.g., while modelling stochastic as well as deterministic signals parametrically 
(Zaknich, 2005). There also arises a problem to reduce the number of operations needed for calculations of statistical moments. Both problems have been solved here, using the recursive approach proposed in the paper. In Section 2, the statement of the problem is presented. In Section 3, recursive expressions for the first and second order central statistics values are worked out. In Section 4, an example is given for any realization of 33 samples. The results of calculation of the total quantity of computer operations are presented in Section 5. Section 6 contains conclusions.

\section{Statement of the Problem}

Assume that we consider a discrete-time signal $U\left(k T_{s}\right) \forall k \in \overline{0, N}$ that is obtained by sampling its continuous-time counterpart $U(t)$ with sampling frequency $F_{s}$. Here $N$ is the general number of samples of the basic signal $U\left(k T_{s}\right) \forall k \in \overline{0, N}$ under consideration; $t$ is a continuous time variable. Suppose, for simplicity, that $N$ is divisible $n$ times by 2 , i.e., $N=2^{n}$. After a multiplex decimation of the realization $u\left(k T_{s}\right) \forall k \in \overline{0, N}$, in the memory of a computer one has a set $\boldsymbol{\Omega}$ of the following sequences:

$x_{1}(k) \equiv u\left(k T_{s}\right) \forall k \in \overline{0, N}, x_{2}(k) \equiv u\left(k 2 T_{s}\right) \forall k \in \overline{0, N / 2}, x_{3}(k) \equiv u\left(k 4 T_{s}\right)$ $\forall k \in \overline{0, N / 4}, \ldots, x_{n-1}(k) \equiv u\left(k n T_{s} / 2\right) \forall k \in \overline{0,2 N / n}, x_{n}(k) \equiv u\left(k n T_{s}\right)$ $\forall k \in \overline{0, N / n}$ of the same signal $U\left(k T_{s}\right) \forall k \in \overline{0, N}$.

Also it is assumed here that the maximal frequency of the last decimated signal $x_{n}(k) \equiv u\left(k n T_{s}\right) \forall k \in \overline{0, N / n}$ is still lower or equal to the new Nyquist frequency $F_{N}$. Then the mean, variance, and autocovariance function values could be calculated by processing different sequences from the set $\Omega$, respectively, using well-known formulas (36), (37) and (38) given in (Bendat and Piersol, 1967).

The aim of the given paper is: firstly, to calculate the abovementioned statistics values without storing decimated sequences in the memory of a computer, secondly, to reduce the number of calculations by applying the recursive approach that will use the information obtained by processing the previously decimated realization from the same set $\Omega$ in the current operation.

\section{Recursive Expressions for Values of the Statistics}

In order to work out the recursive expressions for the first and second central order statistics, let us formulate statements on the calculation of means, variances and covariance function values of decimated realizations as well as non-decimated ones.

COROLlary 1 . The mean $m(\cdot)$ and the variance $\operatorname{var}(\cdot)$ of each realization from the set $\boldsymbol{\Omega}$ are calculated using the recursive expressions of the form

$$
m\left(i T_{s}\right)=\frac{i}{N+i}\left\{\frac{N+2 i}{2 i} m\left(2 i T_{s}\right)+\sum_{l=1}^{\frac{N}{2 i}} u\left(i T_{s}(2 l-1)\right)\right\}
$$




$$
\operatorname{var}\left(i T_{s}\right)=\frac{i}{N+i}\left\{\frac{N+2 i}{2 i} \operatorname{var}\left(2 i T_{s}\right)+\sum_{l=1}^{\frac{N}{2 i}} \dot{u}^{2}\left(i T_{s}(2 l-1)\right)\right\}
$$

$\forall i=1,2,4,8, \ldots, n / 2$, respectively. Here $m\left(i T_{s}\right), m\left(i 2 T_{s}\right)$ and $\operatorname{var}\left(i T_{s}\right), \operatorname{var}\left(i 2 T_{s}\right)$ $\forall i=1,2,4,8, \ldots, n / 2$ are mean and variance values of the current and previous iterations, respectively, and

$$
\dot{u}\left(i T_{s}(2 l-1)\right)=u\left(i T_{s}(2 l-1)\right)-m\left(i T_{s}(2 l-1)\right)
$$

$\forall i=1,2,4,8, \ldots, n / 2$.

COROLlaRY 2. The covariance function values $r_{u}(\cdot)$ of each realization from the set $\Omega$ are calculated using the recursive expression of the form

$$
\begin{aligned}
r_{u}\left(2 \tau i T_{s} ; i T_{s}\right)= & \frac{1}{\frac{N}{i}-2 \tau+1}\left\{\left(\frac{N}{2 i}-\tau+1\right) r_{u}\left(\tau i T_{s} ; 2 i T_{s}\right)\right. \\
& \left.+\sum_{l=1}^{\frac{N}{2 i}-\tau} \dot{u}\left(i T_{s}(2 l-1)\right) \dot{u}\left(i T_{s}(2 l-1+2 \tau)\right)\right\}
\end{aligned}
$$

$\forall i=1,2,4,8, \ldots, n / 2$, where for each $i$ the lag $\tau=0,1,2, \ldots$ in $r_{u}\left(\tau i T_{s} ; 2 i T_{s}\right)$, and

$$
r_{u}\left(\tau i T_{s} ; i T_{s}\right)=\frac{1}{\frac{N}{i}-\tau+1} \sum_{l=0}^{\frac{N}{i}-\tau} \dot{u}\left(i T_{s} l\right) \dot{u}\left(i T_{s}(l+\tau)\right)
$$

$\forall i=1,2,4,8, \ldots, n / 2$, where for each $i$ the lag $\tau=1,3,5, \ldots$ Here $r_{u}\left(2 \tau i T_{s} ; i T_{s}\right)$ and $r_{u}\left(\tau i T_{s} ; 2 i T_{s}\right) \forall \tau=0,1,2,3, \ldots$ are covariance function values of the current and previous iterations, respectively.

Proof of Corollary 1. Let us describe now the signal $u\left(k T_{s}\right) \forall k \in \overline{0, N}$ resolving it into a sum of unit sample sequences $\delta\left(k T_{s}-l T_{s}\right)$ such as (Proakis and Manolakis)

$$
u\left(k T_{s}\right)=\sum_{l=0}^{N} u\left(l T_{s}\right) \delta\left[T_{s}(k-l)\right]
$$

because $\delta\left(k T_{s}-l T_{s}\right)$ is zero everywhere except at $k=l$, where its value is a unity. It follows that the last decimated sequence $x_{n}(k) \equiv u\left(k n T_{s}\right) \forall k \in \overline{0, N / n}$ is

$$
u\left(k n T_{s}\right)=\sum_{l=0}^{\mathrm{N} / \mathrm{n}} u\left(\ln T_{s}\right) \delta\left[T_{s}(k n-\ln )\right]
$$


with the mean

$$
m\left(n T_{s}\right)=\frac{n}{N+n} \sum_{l=0}^{N / n} u\left(\ln T_{s}\right)
$$

and the variance

$$
\operatorname{var}\left(n T_{s}\right)=\frac{n}{N+n} \sum_{l=0}^{N / n} \dot{u}^{2}\left(\ln T_{s}\right)
$$

where $\dot{u}\left(\ln T_{s}\right)=u\left(\ln T_{s}\right)-m\left(n T_{s}\right) \forall l \in \overline{0, N / n}$. It is obvious that samples of the sequence $u\left(k n \frac{T_{s}}{2}\right)$ for $k=0,2,4, \ldots, \frac{2 N}{n}$ are equivalent to the samples of the last decimated sequence $u\left(k n T_{s}\right)$ for $k=0,1,2, \ldots, \frac{N}{n}$, respectively. The other samples of $u\left(k n \frac{T_{s}}{2}\right)$ are newly inserted into sequence $u\left(k n T_{s}\right)$ halving its corresponding time intervals between the next samples, thus increasing the whole number of the samples of sequence (6) twice. Therefore the mean and the variance of the sequence $u\left(k n \frac{T_{s}}{2}\right)$ for $\mathrm{k}=0,2,4, \ldots, \frac{2 N}{n}$ are

$$
m\left(n T_{s} / 2\right)=\frac{n}{2 N+n}\left\{\frac{N+n}{n} m\left(n T_{s}\right)+\sum_{l=1}^{N / n} u\left(T_{s} n(l-1 / 2)\right)\right\}
$$

and

$$
\operatorname{var}\left(n T_{s} / 2\right)=\frac{n}{2 N+n}\left\{\frac{N+n}{n} \operatorname{var}\left(n T_{s}\right)+\sum_{l=1}^{N / n} \dot{u}^{2}\left(T_{s} n(l-1 / 2)\right)\right\}
$$

respectively. Proceeding with that in the reverse order, one could obtain the recursive formulas for calculating means and variances of decimated realizations as well as for the basic one. For the first-decimated realization and for the basic one, those recursive formulas are

$$
m\left(2 T_{s}\right)=\frac{2}{N+2}\left\{\frac{N+4}{4} m(4)+\sum_{l=1}^{N / 4} u(2(2 l-1))\right\}
$$

and

$$
m\left(T_{s}\right)=\frac{1}{N+1}\left\{\frac{N+2}{2} m(2)+\sum_{l=1}^{N / 2} u((2 l-1))\right\}
$$

respectively. Thus, the general expressions for calculating means and variances are of the forms (1) and (2), respectively. 
Proof of Corollary 2. Let us calculate now covariance values of the last decimated realization $x_{n}(k) \equiv u\left(k n T_{s}\right) \forall k \in \overline{0, N / n}$ by the ordinary formula

$$
r_{u}\left(\tau n T_{s} ; n T_{s}\right)=\frac{1}{N-\tau+1} \sum_{l=0}^{\frac{N}{i}-\tau} \dot{u}\left(i \ln T_{s}\right) \dot{u}\left(i \ln T_{s}+\tau n T_{s}\right)
$$

$\forall \tau=0,1, \ldots, L$ with $L<\frac{N}{n}$. Assuming, for clarity of mathematical expressions that $T_{s}=1$. Having in the mind that some samples of the sequence $\dot{u}\left(k n \frac{T_{s}}{2}\right)$ for $\mathrm{k}=0,2,4$, $\ldots, \frac{2 N}{n}$ are equivalent to the respective samples of the last decimated sequence $\dot{u}\left(k n T_{s}\right)$ for $k=0,1,2, \ldots, \frac{N}{n}$, respectively, one can write

$$
\begin{aligned}
r_{u}\left(2 \tau ; \frac{n}{2} T_{s}\right)= & \frac{1}{2 \frac{N}{n}-2 \tau+1}\left\{\left(\frac{N}{n}-\tau+1\right) r_{u}\left(\tau ; n T_{s}\right)\right. \\
& \left.+\sum_{l=1}^{\frac{N}{n}-\tau} \dot{u}\left(n T_{s}\left(l-\frac{1}{2}\right)\right) \dot{u}\left(n T_{s}\left(l-\frac{1}{2}+\tau\right)\right)\right\}
\end{aligned}
$$

$\forall \tau=0,1,2, \ldots$ in $r_{u}\left(\tau n T_{s} ; n T_{s}\right)$, and

$$
r_{u}\left(\tau ; \frac{n}{2} T_{s}\right)=\frac{1}{2 \frac{N}{n}-\tau+1} \sum_{l=0}^{\frac{N}{n}-\tau} \dot{u}\left(\frac{n}{2} T_{s} l\right) \dot{u}\left(\frac{n}{2} T_{s}(l+\tau)\right),
$$

where the lag $\tau=1,3,5, \ldots$ Here $r_{u}\left(2 \tau ; \frac{n}{2} T_{s}\right), r_{u}\left(\tau ; \frac{n}{2} T_{s}\right)$, and $r_{u}\left(\tau ; n T_{s}\right) \forall \tau=$ $0,1,2,3, \ldots$ are covariance function values of the current and previous iterations, respectively.

Continuing that in the reverse order, one could obtain the recursive formulas for calculating covariance values of decimated realizations as well as for a basic one. For the first decimated realization those recursive formulas are

$$
\begin{aligned}
r_{u}\left(2 \tau ; 2 T_{s}\right)= & \frac{1}{\frac{N}{2}-2 \tau+1}\left\{\left(\frac{N}{4}-\tau+1\right) r_{u}\left(\tau ; 4 T_{s}\right)\right. \\
& \left.+\sum_{l=1}^{\frac{N}{4}-\tau} \dot{u}\left(2 T_{s}(2 l-1)\right) \dot{u}\left(2 T_{s}(2 l-1+2 \tau)\right)\right\}
\end{aligned}
$$

$\forall \tau=0,1,2, \ldots$ in $r_{u}\left(\tau ; 4 T_{s}\right)$, and

$$
r_{u}\left(\tau 2 T_{s} ; 2 T_{s}\right)=\frac{1}{\frac{N}{2}-\tau+1} \sum_{l=0}^{\frac{N}{2}-\tau} \dot{u}\left(2 T_{s} l\right) \dot{u}\left(2 T_{s}(l+\tau)\right)
$$

where the lag $\tau=1,3,5, \ldots$. Here $r_{u}\left(\tau ; 2 T_{s}\right), r_{u}\left(\tau ; 2 T_{s}\right)$, and $r_{u}\left(\tau ; 4 T_{s}\right) \forall \tau=$ $0,1,2,3, \ldots$ are covariance function values of the current and previous iterations, re- 
spectively. Finally, for the basic realization $u\left(k T_{s}\right) \forall k \in \overline{0, N}$, we have

$$
\begin{aligned}
& r_{u}\left(2 \tau ; T_{s}\right)= \frac{1}{N-2 \tau+1}\left\{\left(\frac{N}{2}-\tau+1\right) r_{u}\left(\tau ; 2 T_{s}\right)\right. \\
&\left.+\sum_{l=1}^{\frac{N}{2}-\tau} \dot{u}\left(T_{s}(2 l-1)\right) \dot{u}\left(T_{s}(2 l-1+2 \tau)\right)\right\} \\
& \forall \tau=0,1,2, \ldots \text { in } r_{u}\left(\tau ; 2 T_{s}\right), \text { and } \\
& r_{u}\left(\tau ; T_{s}\right)=\frac{1}{N-\tau+1} \sum_{l=0}^{N-\tau} \dot{u}\left(T_{s} l\right) \dot{u}\left(T_{s}(l+\tau)\right),
\end{aligned}
$$

where the lag $\tau=1,3,5, \ldots$. Here $r_{u}\left(2 \tau ; T_{s}\right), r_{u}\left(\tau ; T_{s}\right)$, and $r_{u}\left(\tau ; 2 T_{s}\right) \forall \tau=$ $0,1,2,3, \ldots$ are covariance function values of the current and previous iterations respectively. Thus, the general expressions for calculating covariance values of decimated realizations and of the basic sequence are of the form (4) and (5), respectively.

\section{Example}

Let us now calculate the mean, variance, and covariance values having any realization of the basic non-decimated discrete-time signal $U\left(k T_{s}\right) \forall k \in \overline{0, N}$ with $\mathrm{N}=32$ and arbitrary $T_{s}$. After decimating this realization, we get the set $\boldsymbol{\Omega}$ of realizations: $u\left(T_{s} k\right)$ $\forall k \in \overline{0,32}, u\left(2 T_{s} k\right) \forall k \in \overline{0,16}, u\left(4 T_{s} k\right) \forall k \in \overline{0,8}, u\left(8 T_{s} k\right) \forall k \in \overline{0,4}$ or $u(k) \forall k \in$ $\overline{0,32}, u(2 k) \forall k \in \overline{0,16}, u(4 k) \forall k \in \overline{0,8}, u(8 k) \forall k \in \overline{0,4}$ assuming, for simplicity, that $T_{s}=1$.

First of all, we calculate the mean, variance and covariance values of the last decimated realization by the ordinary formulas:

$$
\begin{aligned}
& m(8)=\frac{1}{5} \sum_{l=0}^{4} u(8 l)=\frac{1}{5}[u(0)+u(8)+u(16)+u(24)+u(32)] \\
& \operatorname{var}(8)=\frac{1}{5} \sum_{l=0}^{4} \dot{u}^{2}(8 l)=\frac{1}{5}\left[\dot{u}^{2}(0)+\dot{u}^{2}(8)+\dot{u}^{2}(16)+\dot{u}^{2}(24)+\dot{u}^{2}(32)\right],
\end{aligned}
$$

and

$$
r_{u}(\tau ; 8)=\frac{1}{4-\tau+1} \sum_{l=0}^{4-\tau} u(\dot{8} l) \dot{u}(8 l+8 \tau)
$$

for $\tau=1,2,3$, respectively. Here $\dot{u}(8 l)=u(8 l)-m(8) \forall l \in \overline{0,4}$.

Next, the decimated realization $u(4 k) \forall k \in \overline{0,8}$ has been found by inserting the respective samples of the basic realization into $u(8 k) \forall k \in \overline{0,4}$. They halve the corresponding time intervals between the adjacent samples of the last decimated realization 
increasing the number of data. Then the statistics of $u(4 k) \forall k \in \overline{0,8}$ are calculated according to recursive expressions (1)-(5) as follows:

$$
\begin{aligned}
m(4) & =\frac{4}{32+4}\left\{\frac{32+8}{8} m(8)+\sum_{l=1}^{4} u(4(2 l-1))\right\} \\
& =\frac{1}{9}[5 m(8)+u(4)+u(12)+u(20)+u(28)], \\
\operatorname{var}(4) & =\frac{4}{32+4}\left\{\frac{32+8}{8} \operatorname{var}(8)+\sum_{l=1}^{4} \dot{u}^{2}(4(2 l-1))\right\} \\
& =\frac{1}{9}\left[5 \operatorname{var}(8)+\dot{u}^{2}(4)+\dot{u}^{2}(12)+\dot{u}^{2}(20)+\dot{u}^{2}(28)\right], \\
r_{u}(2 \tau ; 4) & =\frac{1}{8-2 \tau+1}\left\{(4-\tau+1) r_{u}(\tau ; 8)+\sum_{l=1}^{4-\tau} \dot{u}(8 l-4) \dot{u}(8 l-4+8 \tau)\right\},
\end{aligned}
$$

if $\tau=1,2$ in $r_{u}(\tau ; 8)$,

$$
r_{u}(\tau ; 4)=\frac{1}{8-\tau+1} \sum_{l=0}^{8-\tau} \dot{u}(4 l) \dot{u}(4 l+4 \tau)
$$

for $\tau=1,3$, respectively. Here $\dot{u}(4 l)=u(4 l)-m(4) \forall l \in \overline{0,8}$. Using the same recursive expressions, we get the statistics of the first decimated realization $u(2 k) \forall k \in \overline{0,16}$

$$
\begin{aligned}
m(2)= & \frac{2}{32+2}\left\{\frac{32+4}{4} m(4)+\sum_{l=1}^{8} u(2(2 l-1))\right\} \\
= & \frac{1}{17}[9 m(4)+u(2)+u(6)+u(10)+u(14) \\
& +u(18)+u(22)+u(26)+u(30)],
\end{aligned}
$$

the variance

$$
\begin{aligned}
\operatorname{var}(2)= & \frac{2}{32+2}\left\{\frac{32+4}{4} \operatorname{var}(4)+\sum_{l=1}^{8} \dot{u}^{2}\left(2 T_{s}(2 l-1)\right)\right\} \\
= & \frac{1}{17}\left[9 \operatorname{var}(4)+\dot{u}^{2}(2)+\dot{u}^{2}(6)+\dot{u}^{2}(10)+\dot{u}^{2}(14)\right. \\
& \left.+\dot{u}^{2}(18)+\dot{u}^{2}(22)+\dot{u}^{2}(26)+\dot{u}^{2}(30)\right]
\end{aligned}
$$

and

$$
r_{u}(2 \tau ; 2)=\frac{1}{16-2 \tau+1}\left\{(8-\tau+1) r_{u}(\tau ; 4)+\sum_{l=1}^{8-\tau} \dot{u}(4 l-2) \dot{u}(4 l-2+4 \tau)\right\},
$$


if $\tau=1,2$ in $r_{u}(\tau ; 4)$,

$$
r_{u}(\tau ; 2)=\frac{1}{16-\tau+1} \sum_{l=0}^{16-\tau} \dot{u}(2 l) \dot{u}(2 l+2 \tau)
$$

for $\tau=1,3$, respectively. Here $\dot{u}(2 l)=u(2 l)-m(2) \forall l \in \overline{0,16}$. Finally, we obtain the statistics of the basic non-decimated realization $u(k) \forall k \in \overline{0,32}$

$$
\begin{aligned}
m(1)=\frac{1}{32+1}\left\{\frac{32+2}{2} m(2)+\sum_{l=1}^{16} u(2 l-1)\right\} \\
=\frac{1}{33}(17 m(2)+u(1)+u(3)+u(5)+u(7)+u(9)+u(11), \\
u(13)+u(15)+u(17)+u(19)+u(21)+u(23)+u(25) \\
+u(27)+u(29)+u(31))
\end{aligned}
$$

the variance

$$
\begin{aligned}
\operatorname{var}(1)= & \frac{2}{32+2}\left\{\frac{32+4}{4} \operatorname{var}(2)+\sum_{l=1}^{16} \dot{u}^{2}(2 l-1)\right\} \\
= & \frac{1}{33}\left(17 m(2)+\dot{u}^{2}(1)+\dot{u}^{2}(3)+\dot{u}^{2}(5)+\dot{u}^{2}(7)+\dot{u}^{2}(9)+\dot{u}^{2}(11)\right. \\
& \dot{u}^{2}(13)+\dot{u}^{2}(15)+\dot{u}^{2}(17)+\dot{u}^{2}(19)+\dot{u}^{2}(21)+\dot{u}^{2}(23)+\dot{u}^{2}(25) \\
& \left.+\dot{u}^{2}(27)+\dot{u}^{2}(29)+\dot{u}^{2}(31)\right)
\end{aligned}
$$

and

$$
r_{u}(2 \tau ; 1)=\frac{1}{32-2 \tau+1}\left\{(16-\tau+1) r_{u}(\tau ; 2)+\sum_{l=1}^{16-\tau} \dot{u}(2 l-1) \dot{u}(2 l-1+2 \tau)\right\}
$$

for $\tau=1,2$ in $r_{u}(\tau ; 2)$,

$$
r_{u}(\tau ; 1)=\frac{1}{32-\tau+1} \sum_{l=0}^{32-\tau} \dot{u}(l) \dot{u}(l+\tau)
$$

for $\tau=1,3$, respectively. Here $\dot{u}(l)=u(l)-m(1) \forall l \in \overline{0,32}$.

It should be noted that one can calculate the same mean and variance values by the ordinary formulas (36), (37) and (38), too. However, recursive calculations according to the formulas (1)-(5) allow us to decrease the number of summing operations as compared with ordinary expressions given in (Bendat and Piersol, 1967), especially, for large enough $N$. In such an example, while calculating $m(4), m(2)$ and $m(1)$, we avoid five, nine and seventeen summing operations, respectively. By calculating $\operatorname{var}(4), \operatorname{var}(2)$, and 
$\operatorname{var}(1)$, we double the numbers of operations to be saved. In addition we avoid four and three, eight and seven, sixteen and fifteen summing operations while calculating the covariance values by (26), (30) and (34), correspondingly. In general, having any realization consistin $\mathrm{g}$ of 33 samples one needs 115 less summing operations while calculating the statistics of decimated and non-decimated realizations in comparison with the operations performed using the ordinary formulas. On the other hand, in such an example there appear several additional multiplication operations in each recursive step, as shown in (Pupeikis, 2007).

\section{Total Amount of Computer Operations}

Thus, recursive calculations using formulas (1), (2), and (4) allow us to decrease the quantity of computer summing operations as compared to the ordinary expressions:

$$
\begin{aligned}
& \bar{u}=\frac{1}{N} \sum_{k=1}^{N} u_{k}, \\
& \bar{x}^{2}=\frac{1}{N} \sum_{k=1}^{N}\left(x_{k}\right)^{2},
\end{aligned}
$$

and

$$
R_{r}=R_{x}(r h)=\frac{1}{N-r} \sum_{k=1}^{\mathrm{N}-\mathrm{r}} x_{k} x_{k+r}, \quad r=0,1,2, \ldots, m,
$$

used to determine the mean, variance, and covariance function values, respectively. It could be noted that in (36), (37), and (38), the markings and notation given in (Bendat and Piersol, 1967) are kept. Here $u_{k}$ are sample values of the continuous time function $u(t)$ at points $t_{k}=t_{0}+k h$ for $k=1,2, \ldots, N$ (point $t_{0}$ is chosen, arbitrarily and it is not included in the abovementioned formulas); $h$ is equivalent to the sampling period $T_{s}$ in expressions (1), (2), and (4); the sequence $\left\{x_{k}\right\}$ is determined by centering the sequence $\left\{u_{k}\right\}$, i.e., $x_{k}=u_{k}-\bar{u}$ for $k=1,2, \ldots, N$.

The total amount of computer operations could be calculated by

$$
O_{1}=\sum_{k=0}^{n-1} \frac{N}{2^{k}}+5 n,
$$

for the mean,

$$
O_{2}=2 \sum_{k=0}^{n-1} \frac{N}{2^{k}}+6 n
$$


for the variance, and

$$
O_{3}=\sum_{l=0}^{n}\left\{2\left[\left(\frac{N}{2^{l}}+1\right)\left(\frac{\mathrm{m}}{2^{l}}+1\right)-\sum_{k=0}^{\frac{\mathrm{m}}{2^{l}}} k\right]+5\left(\frac{\mathrm{m}}{2^{l}}+1\right)\right\}
$$

for the covariance function values, respectively, if we process one realization of initial nondecimated and $n$ realizations of decimated signals, using formulas (36), (37), and (38). On the other hand, $\mathrm{O}_{1}, \mathrm{O}_{2}, \mathrm{O}_{3}$ turn out to be

$$
\begin{aligned}
& \widetilde{O}_{1}=N+8 n, \\
& \widetilde{O}_{2}=2 N+8 n,
\end{aligned}
$$

and

$$
\begin{aligned}
\widetilde{O}_{3}= & \sum_{l=1}^{n}\left\{2\left[\left(\frac{N}{2^{l}}+1\right)\left(\frac{\mathrm{m}}{2^{l}}+1\right)-\sum_{k=0}^{\frac{\mathrm{m}}{2^{(l-1)}}} 2 k\right]+11\left(\frac{\mathrm{m}}{2^{l}}+1\right)\right\} \\
& +\sum_{l=1}^{n}\left\{2\left[\frac{N}{2^{(l-1)}} \frac{\mathrm{m}}{2^{l}}-\sum_{k=0}^{\frac{\mathrm{m}}{2^{(l-1)}}}(2 k-1)\right]+5\left(\frac{\mathrm{m}}{2^{l}}+1\right)\right\} \\
& +2\left[\left(\frac{N}{2^{n}}+1\right)\left(\frac{\mathrm{m}}{2^{n}}+1\right)-\sum_{k=0}^{\frac{\mathrm{m}}{2^{n}}} k\right]+5\left(\frac{\mathrm{m}}{2^{n}}+1\right),
\end{aligned}
$$

respectively, if recursive expressions (1), (2), (4) are applied in the calculation of the mean, variance, and covariance function values. The covariance function values have been calculated using the recommendation given in (Bendat and Piersol, 1967) in respect of the $m$ value in expression (38). The authors recommend there to choose $m$ not more than $0.1 N$. Note that, in our case, $N$ depends on $T_{s}$. Thus, for different realizations $m$ is varying, as well. The values of $O_{1}, O_{2}, O_{3}, \widetilde{O}_{1}, \widetilde{O}_{2}, \widetilde{O}_{3}$ have been determined for varying numbers of realizations in the set $\Omega$ by increasing the general number of realizations $Q_{R}$ from $Q_{R}=1$ (only last decimated signal in the set $\Omega$ with $N_{10}=32$ and $m_{10}=2$ ) to $Q_{R}=10$ (all $n=9$ decimated realizations and non-decimated realization of the initial signal with $N_{1}=16384$ and $\left.m_{1}=1024\right)$. The values of $N$ for each decimated realization decrease two times. Thus, for the first decimated sequence $N_{2}=8192$, while for the last one $N_{10}=32$. In such a case, the $m$ values decrease, too. For the initial nondeci mated realization $m_{1}=1024$ is chosen. Then, for decimated realizations, the values of $m_{i}, i=\overline{2,10}$ are: $512,256,128,64,32,16,8,4$, and 2 . The results of calculation of the total quantity of computer operations for both methods are given in Table 1 and Figs. 1, 2. Note that, in the calculation of values $O_{1}, O_{2}, O_{3}, \widetilde{O}_{1}, \widetilde{O}_{2}, \widetilde{O}_{3}$ for each varying $Q_{R}$ only samples of one at least decimated realization in the set $\Omega$ have been used despite which expressions - ordinary or recursive - are applied. Thus, we process samples of the last decimated realization for $Q_{R}=1$, samples of the first decimated realization for $Q_{R}=9$, and samples of initial non-decimated realization for $Q_{R}=10$, respectively. It should be noted that, by increasing $Q_{R}$ in the set $\Omega$ more than by five realizations, the quantity 
Table 1

Dependence of $O_{1}, \widetilde{O}_{1}, O_{2}, \widetilde{O}_{2}, O_{3}, \widetilde{O}_{3}$, on $Q_{R}$ in the set $\boldsymbol{\Omega}$ while calculating their mean, variance, and covariance values. The first line for each $Q_{R}$ corresponds to the computer operations values $O_{1}, O_{2}, O_{3}$, while the second line - to the values $\widetilde{O}_{1}, \widetilde{O}_{2}, \widetilde{O}_{3}$, respectively

\begin{tabular}{rrrr}
\hline$Q_{R}$ & $O_{1}, \widetilde{O}_{1}$ & $O_{2}, \widetilde{O}_{2}$ & $O_{3}, \widetilde{O}_{3}$ \\
\hline 1 & 37 & 70 & 207 \\
& 37 & 70 & 207 \\
\hline 2 & 69 & 134 & 655 \\
& 40 & 72 & 430 \\
\hline 3 & 133 & 262 & 2295 \\
& 72 & 136 & 1482 \\
\hline 4 & 261 & 518 & 8687 \\
& 136 & 264 & 5506 \\
\hline 5 & 517 & 1030 & 33495 \\
& 264 & 520 & 21234 \\
\hline 6 & 1029 & 2054 & 131495 \\
& 520 & 1032 & 83410 \\
\hline 7 & 2053 & 4102 & 521031 \\
& 1032 & 2056 & 330642 \\
\hline 8 & 4101 & 8198 & 2074247 \\
& 2056 & 4104 & 1316626 \\
\hline 9 & 8197 & 16390 & 8277255 \\
& 4104 & 8200 & 5254674 \\
\hline 10 & 16389 & 32774 & 335943375 \\
& 8200 & 16392 & 20995090 \\
\hline \multirow{2}{*}{5} & & & \\
\hline
\end{tabular}

of computer operations increases considerably despite which expressions-ordinary or recursive-are used. On the other hand, the recursive expressions guarantee much smaller quantity of computer operations as compared with the ordinary ones, especially when calculating the covariance values of realizations (see Table 1 and Fig. 2).

\section{Conclusions}

The number of operations for calculating the mean, variance, and covariance values of nondecimated and decimated signal realizations could be essentially reduced using recursive formulas (1), (2), (4) (see Table 1 and Figs. 1, 2). In such a case, there is no need to store the whole set of decimated realizations in the memory of a computer, only the basic non-decimated realization is required. 


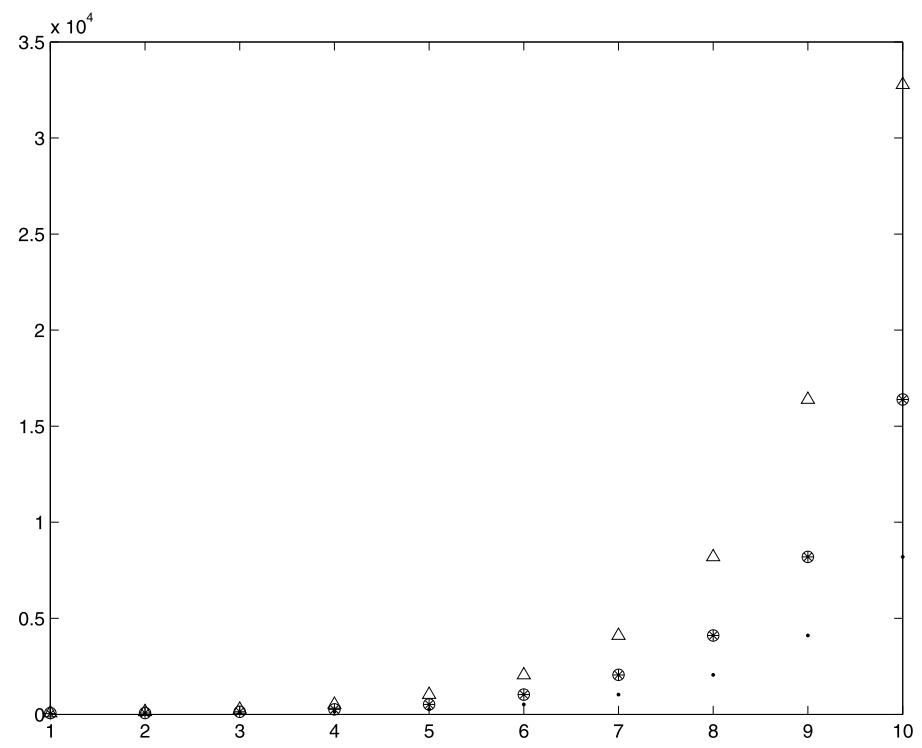

Fig. 1. Dependence of $O_{1}, O_{2}, \widetilde{O}_{1}, \widetilde{O}_{2}$ on $Q_{R}$ while calculating their mean and variance values: $x$-axis values of $Q_{R}$ in the set $\boldsymbol{\Omega}, y$-axis - numbers of computer iterations. $O_{1}, O_{2}, \widetilde{O}_{1}, \widetilde{O}_{2}$, are marked by $*, \Delta$, . and $\circ$, respectively.

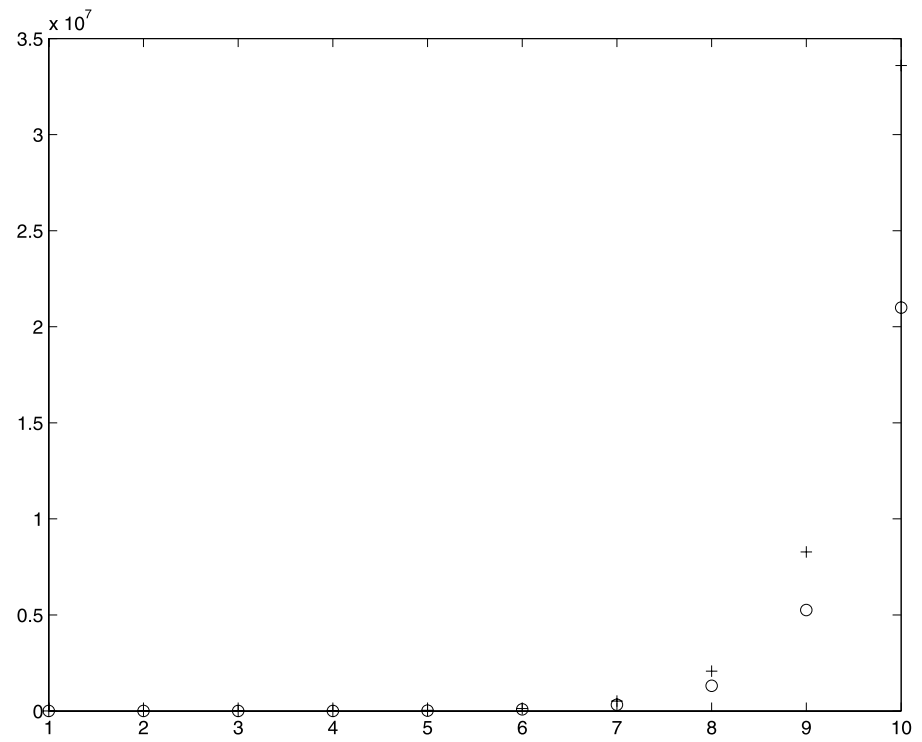

Fig. 2. Dependence of $O_{3}, \widetilde{O}_{3}$ on $Q_{R}$ while calculating their correlation values. $O_{3}, \widetilde{O}_{3}$ are marked by + and $\circ$, respectively. Other values and markings are the same as in Fig. 1. 


\section{References}

Ȧström (1969). On the choice of sampling rates in parametric identification of time series. Information Sci., 1 , 273-278.

Bendat, J.S., and A.G. Piersol (1967). Measurement and Analysis of Random Data. John Wiley \& Sons, N.Y.

Liu, B., and F. Mintzer (1978). Calculation of narrow-band spectra by direct decimation. IEEE Trans. Acoust., Speech, Signal Processing, ASSP-26, 529-534.

Ljung, L. (1999). System Identification. Theory for the User. 2nd edition. Prentice-Hall PTR.

MacGregor, J.F. (1976). Optimal choice of the sampling interval for discrete process control. Technometrics, 18(2), 151-160.

Quirk, M.P., and B. Liu (1983). Improving resolution for autoregressive spectral estimation by decimation. IEEE Trans. Acoust., Speech, Signal Processing, ASSP-31, 630-637.

Payne, R.L., G.C. Goodwin and M.B. Zarrop (1975). Frequency domain approach for designing sampling rates for system identification. Automatica, 11, 189-191.

Proakis, J.G., and D.G. Manolakis (1996). Digital Signal Processing: Principles Algorithms and Applications. Prentice-Hall, London.

Pupeikis, R. (2007). On recursive expressions for statistics of decimated sequences. Liet. matem. rink., 47(spec. issue), 411-416.

Villalba, M., and B.K. Walker (1989). Spectrum manipulation for improved resolution. IEEE Trans. Acoust., Speech, Signal Processing, ASSP-17(6), 820-831.

Wang, S., X. Guan, D. Wang, X. Ma and Y. Su (2007). Adaptive selection of sampling interval in frequency domain for estimating the poles of scatterers. Piersonline, 3(1), 106-110.

Xin, J., H. Tsuji and A.Sano (1995). Optimal sampling interval for system identification based on decimation and interpolation. IEE Proc.-Control Theory Appl., 142(1), 15-22.

Zaknich, A. (2005). Principles of Adaptive Filters and Self-Learning Systems. Springer.

R. Pupeikis received PhD degree from the Kaunas Polytechnic Institute, Kaunas, Lithuania, 1979. He is a senior researcher at the Process Recognition Department of the Institute of Mathematics and Informatics and an associated professor at the Gediminas Technical University. His research interest include the digital signal processing, robust approaches of dynamic system identification as well technological process control. 


\section{Apie decimuotu signalu apdorojima}

\section{Rimantas PUPEIKIS}

Straipsnyje pasiūlytas rekurentinis decimuotų sekų statistikų skaičiavimo metodas, leidžiantis žymiai sumažinti skaičiavimo operacijų skaičių. Decimuotos sekos gaunamos išrenkant tam tikras pradinio diskretaus laiko signalo, gauto diskretizavus analoginị signalą, atskaitas. Nauja seka lyginant su prieš ją esančia esti sudaryta padvigubinus pradinị diskretizavimo periodą. Pastarasis dvigubinamas tol, kol naujasis Naikvisto dažnis neperžengia pradinio signalo maksimalaus dažnio. Pasiūlytas statistiku skaičiavimo metodas, kuris tam tikrą statistinị momentą, kaip antai, vidurkị, dispersiją bei kovariaciją, skaičiuoja rekurentiškai taikydamas informaciją, gautą apdorojus prieš esančią decimuotą seką. Atkrenta būtinybè decimuotas sekas saugoti kompiuterio atmintinèje pakanka joje turèti pradinio diskretaus laiko signalo atskaitas. Darbe įrodyti teiginiai, kuriu pagrindu sukurtos rekurentinès išraiškos. Pateiktas statistikų skaičiavimo pavyzdys bei skaičiavimo operacijų skaičių išraiškos. Gauti eksperimentų rezultatai. 